\title{
Analysis of the Drop-in Operation of a Refrigeration System by the Response Surface Methodology
}

Victor Hugo Panato, Marcus Almeida Queiroz, Luis Manoel Paiva Souza, Arthur Heleno Pontes Antunes and Enio Pedone Bandarra Filho

LEST nano, Federal University of Uberlandia, Uberlandia 38400-902, Brasil

Received: August 08, 2016 / Accepted: August 23, 2016 / Published: December 31, 2016.

\begin{abstract}
The objective of this study is to evaluate the gains in a drop-in process of refrigerants in a basic refrigeration system using the RSM (response surface methodology) to optimization. A central composite design and analysis of variance are also used. In addition, the model will be analyzed and compared to experimental results, consolidating various parameters to get the best regions in a broad universe of options, with a reduced number of experiments. The RSM is a set of statistical tool, which describes the entire region of interest through experimental specific points, by appropriate polynomial equation. The experimental results were extracted from a cooling test bench compound for a reciprocating compressor, evaporator, condenser and expansion valve. R22, R290, R1270, R438A, R404A, R134a, R410A and R32 were tested at the same experimental apparatus, the lubricating oil was replaced in some cases. The higher value of coefficient of performance and cooling capacity were investigated. The results obtained with the response surface methodology technique showed good agreement with the experimental work, (coefficient of determination exceeding 0.8) which indicates, good representation of the output variables of the cooling system. The tested optimization tools were able to identify areas of maximum, allowing for better comparison of results obtained by different refrigerants.
\end{abstract}

Key words: Optimization, response surface methodology, dropin, alternative fluids.

$\begin{array}{ll}\text { Nomenclature } \\ \text { AVEE } & \text { Degree of opening of electronic expansion valve } \\ C C D & \text { Central composite design } \\ C O P & \text { Coefficient of performance } \\ \text { GWP } & \text { Global warming potential } \\ \text { LTB } & \text { Larger the best } \\ N T B & \text { Nominal the best } \\ \text { ODP } & \text { Ozone depletion potential } \\ Q & \text { Cooling capacity } \\ R 2 & \text { Coefficient of determination } \\ R 2 b & \text { Adjusted coefficient of determination } \\ R S M & \text { Response surface methodology } \\ S C & \text { Subcooling } \\ S H & \text { Superheat } \\ S T M & \text { Smaller the best } \\ T & \text { Temperature }\end{array}$

\section{Subscript}

2 Compressor outlet

Corresponding author: Victor Hugo Panato, master, research field: alternative fluids.

$\begin{array}{ll}8 & \text { Evaporator inlet-water side } \\ C P & \text { Compressor } \\ E V & \text { Evaporator } \\ V E E & \text { Electronic expansion valve }\end{array}$

\section{Introduction}

The replacement of refrigerants that destroy the ozone layer by options null ODP (ozone depletion potential) had a landmark the Montreal Protocol [1]. Since then, many studies have been developed to find alternative fluid to chlorofluorocarbons and hydrofluorocarbons.

With the development of studies, several fluid options were evaluated, including hydrofluorocarbons, that does not have the element chlorine and does not impact the ozone layer, but mainly, they have a high impact on the greenhouse effect. Hydrocarbons, one of the first fluid used in refrigeration, in the 19th century, returned to be analyzed as an alternative because it does not impact the ozone layer and has low 
contribution to the greenhouse effect (low GWP (global warming potential)). Against these fluids, there is concern in its use due to its high inflammability.

In addition to new fluids and new technologies for next generation of equipment's, research to reduce the environmental impact has a task force that analyzes the condition of the legacy, existing equipment's in full operation and lifespan. For this group, the drop-in and retrofit are possibilities to keep their operating conditions, with low environmental impact and if is possible, improving energy efficiency and cooling capacity. The drop-in is a simple replacement, only the refrigerant (sometimes the oil), while the retrofit is a updating the equipment for replacement or refurbishment of its components. Because of the diversity of equipment installed and their different behaviors, many experimental researches of drop-in and retrofit have been developed.

The subjects of simulation and optimization, together with the statistical design, have been developed new research in this area. In general, we can say that these tools enable gains with time, availability and costs for experiments and technical personnel [2].

Next is to show an analysis using the design of experiments with the response surface methodology and desirability function to find the points of best operational and specific refrigeration capacity of each fluid, to evaluate the statistical tools on the comparison of alternative fluids to R22. The data were extracted from an experimental research performed on a test bench with reciprocating compressor. A validation work is also discussed in the text together.

\section{Literature Survey}

The use of statistical tools collaborates in experimental work in several ways: defining limits, better performance regions, better sets, etc. The designed experiments was presented by Box and Wilson [3]. It allows for analysis of changes on controllable variables and their impact on the results of experiments [4].

The correct choice of treatment of statistical methods can reduce the number of experiments required [5]. According Neto et. al. [6], the CCD (central composite design) is a second-order model comprising:

- Factorial points (vertices) with coordinates $x_{i}= \pm 1$, for all $i=1,2, \ldots k$, where $k$ is the number of factors;

- Star points (axial) that allows the estimation of the quadratic effects and curl effects $(\propto>1)$;

- Center point used repeatedly for pure error identification (lack of fit).

RSM (response surface methodology) is a set of mathematical and statistical techniques used to represent (visualize) models and analyze engineering problems [7]. The RSM can be utilized to select the best pointor region of a dependent variable or, the biggest effects of factors [8]. Aslan [9] utilized the RSM to establish a relationship between three variables of a Multi-Gravity Separator and determine the optimal operating point.

The mathematical model of Response Surface is represented in Eq. (1).

$Y=b_{0}+\sum_{i=1}^{k} b_{i} X_{i}+\sum_{i=1}^{k} b_{i i} X_{i}^{2}+\sum_{i>j}^{k} \sum_{j}^{k} b_{i i} X_{i} X_{j}+e$

where,

$X_{i}$ : are the independents factors;

$b_{0}$ : is the intercept (zero point);

$b_{i}:$ is the first orden coefficient of the model;

$b_{i i}$ : is the quadractic coefficient of the factor;

$b_{i j}$ : is the linear coefficient of the model for the interaction between factors;

$k$ : is the number of factor studied and optimized and

$e:$ is the experimental error.

Dharma et al. [10] adopted the RSM to optimize the biodiesel production process. With an experimental 
design of the Box-Behnken type, they obtained good fits curves (the analysis of $R^{2}$ and $\bar{R}^{2}$ ) and identified the optimal operating parameters for transesterification.

For checking the fit, test of importance of the factors and quality of the model, it was utilized the ANOVA [11]. The lack of fit of model was evaluated with $95 \%$ confidence level. The coefficient of determination $\left(R^{2}\right)$ and adjusted coefficient of determination $\left(\bar{R}^{2}\right)$ were checked for analyzing the proportion represented by the model. The higher the value of the coefficient of determination, the more precise is the model [12].

Since the objective is to analyze the composite system (several dependent variables simultaneously), the analysis should be carried out by combining the model representing each parameter, known as multivariate optimization.

The optimization techniques help us to understand and maximize (minimize) the effects from the interaction between the factors, indicating the region of interest [13].

Rodrigues et al. [14] investigated the methods of compromise programming and goal programming comparing the results with the method of the desirability function. They identified that the method of goal programming can get stuck to the points of optimal local, nevertheless, presented results higher than those found by the method of Derringer and Suich [15].

In the case where the response surfaces already exist, the overlap of these is an acceptable alternative [16]. The location of the best result region will be performed by visual analysis. This method has limited application to impose restriction, as in the case of the evaporation temperature $\left(T_{E V}\right)$ and cooling capacity $\left(Q_{E V}\right)$ for this job.

The desirability function, suggested by Derringer and Suich and then modified by Derringer [17], is a method that combines the equations (models) into a single equation using weights for each variable. They suggested individual functions that can assume values between 0 , for a completely undesirable response and 1, fully desired response [18].

The combination of individual functions gives rise to Global Desirability. This should be maximized/minimized to obtain the point of interest, optimizing at once all variables. The desirability function includes 3 different types of response [19]:

(1) NTB (Nominal-the-best): Where you want the estimated response reach a particular target value;

(2) STB (Smaller-the-best): Where you want the estimated response is less than an upper limit;

(3) LTB (Larger-the-best): Where you want the estimated response is greater than a lower limit.

The mathematical description of individual Desirability function $\left(d_{i}\right)$ is presented in Eq. (2) [8, 20],

$$
d_{i}=\left\{\begin{array}{cc}
0 & \text { if } y<L \\
\left(\frac{y-L}{T-L}\right)^{s} & \text { if } L \leq y \leq T \\
1 & \text { if } y>T
\end{array}\right\}
$$

where, $L$ is the lower acceptable value and $T$ is the target value. $y$ is the response that wants to maximize (LTB) and $s$ is the weight.

Thus, the desirability of individual functions defined, the global function is written by the arithmetic average of the individual functions

$$
D=\left(d_{1} \times d_{2} \times \ldots \times d_{n}\right)^{1 / n}
$$

where, $n$ is the number of individual responses that want optimum.

A relevant feature of the desirability function is that it becomes null when any of the answers is outside the region of interest, due to the use of the geometric mean.

\section{Results and Discussion}

The drop-in operation was carried out on a test bench in Energy, Thermal Systems and Nanotechnology Laboratory (LEST nano) of the Federal University of Uberlandia in order to evaluate the options of alternative fluids from R22. The main 
cooling system is constituted by a reciprocating compressor developed for R22, electronic expansion valve and two tube in tube heat exchanger. The details of the equipment are presented in Table 1. One frequency converter was used to modulate the compressor operating speed. Auxiliary equipment's such as load bank to simulate the thermalload, cooling tower, pumps, etc. are used for the functioning of cooling system but not detailed in this text. Fig. 1 shows a schematic drawing of the experimental bench. The calculation of the uncertainty of measurement was carried out through software ESS, considering the individual values of each instrument.

The refrigerants utilized in this bench are presented in Table 2, together with the mass used (load of refrigerant) and operational limits.

Data collection was performed in steady state conditions. Operating limits are used to prepare the experimental design, performed with the aid of statistical software. Each set of tests performed (with a refrigerant), a drop-in operation was carried out, where, the refrigerant already tested was removed, the system was vacuumed until the internal pressure reaches $400 \mu \mathrm{mHg}$, and the new refrigerant has been added. Mineral oil was used for the fluids R22, R290, R1270 and R438A. During the replacement of the R438A by R404A, it was performed replacing the lubricating by a polyolester oil, compatible with the fluids not yet tested (R404A, R134a, R410A and R32). For each refrigerant, were performed 13 experiments, being 5 in the center point for the identification of experimental error, according to the experimental design.

The experimental bench has always operated with the adjusted factors as planning $\left(A_{V E E}\right.$ and $\left.F_{C P}\right)$. The thermal reservoir has the function of heat exchange with the refrigerant in the evaporator. The water inlet temperature $\left(T_{8}\right)$ and mass flow in the evaporator, were established and maintained in $20^{\circ} \mathrm{C}$ and $0.35 \mathrm{~kg} / \mathrm{s}$, respectively, during the tests. The other parameters

Table 1 Equipment used in the main experimental facility.

\begin{tabular}{llll}
\hline Equipment & Category & Model & Nominal capacity $(\mathrm{kW})$ \\
\hline Compressor & Reciprocating & Octagon 2DC-3.2 & 7.6 \\
Condenser & Tube in tube & & 26.2 \\
Evaporator & Tube in tube & & 17.5 \\
Expansion valve & Electronic & E2V18BRB00 & \\
\hline
\end{tabular}

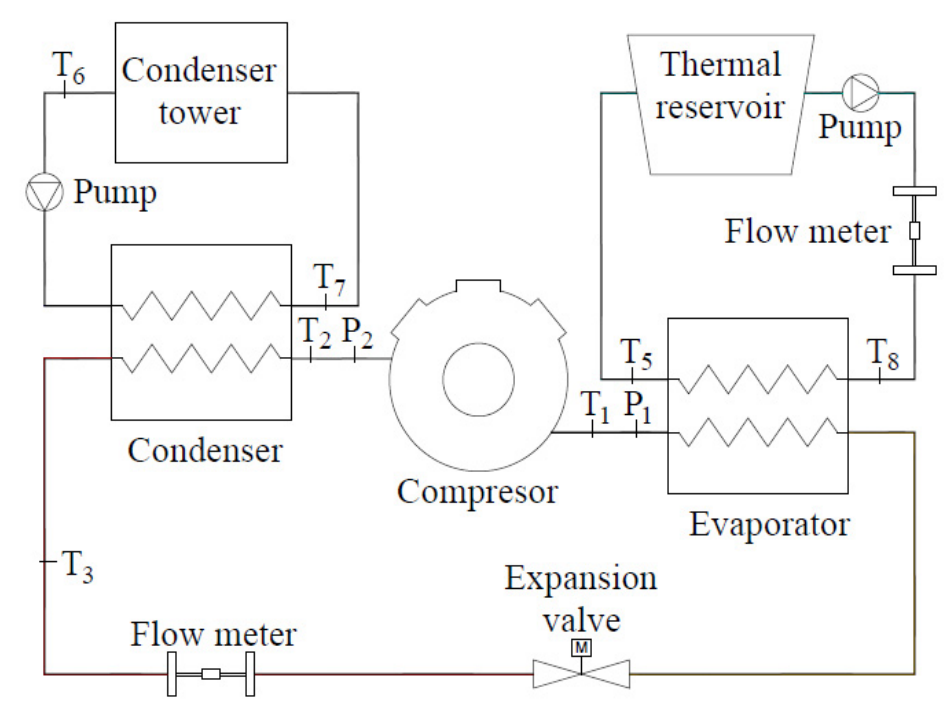

Fig. 1 Schematic drawing of the experimental bench. 
Table 2 Refrigerants in analysis and operational limits: Compressor operating frequency $\left(F_{C P}\right)$ and degree of opening of electronic expansion valve $\left(A_{V E E}\right)$.

\begin{tabular}{llllllll}
\hline \multirow{2}{*}{ Fluid } & \multirow{2}{*}{ Charge $(\mathrm{kg})$} & \multicolumn{3}{c}{$\mathrm{F}_{\mathrm{CP}}(\mathrm{Hz})$} & \multicolumn{3}{c}{$\mathrm{A}_{\mathrm{VEE}}(\%)$} \\
\cline { 3 - 8 } & & Bottom & Central & Upper & Bottom & Central & Upper \\
\hline R22 & 3.2 & 40 & 50 & 60 & 50 & 70 & 90 \\
R290 & 1.5 & 40 & 50 & 60 & 50 & 70 & 90 \\
R1270 & 1.5 & 40 & 50 & 60 & 50 & 70 & 90 \\
R438A & 3.0 & 40 & 50 & 60 & 50 & 70 & 90 \\
R404A & 2.4 & 40 & 50 & 60 & 50 & 70 & 90 \\
R134a & 3.2 & 40 & 50 & 60 & 45 & 55 & 65 \\
R410A & 3.0 & 35 & 40 & 45 & 35 & 45 & 55 \\
R32 & 1.9 & 35 & 40 & 45 & 35 & 45 & 55 \\
\hline
\end{tabular}

were collected when reached steady state. Coriolis Mass Flowmeter was used to measure the mass flow of refrigerant in the system. Temperature sensors type PT100 and piezoresistive pressure sensor were distributed on the test bench according to Fig. 1. The cooling capacity was calculated using the mass flow of refrigerant and the enthalpy of the fluid in the inlet and outlet of the evaporator. The energy consumed by the compressor was read directly on the frequency converter.

The degree of superheat $(\mathrm{SH})$ and subcooling $(\mathrm{SC})$ of the refrigerant at the evaporator and condenser outlet, respectively, were not controlled and achieved wide range of results, including values above the usual (SH higher than $40{ }^{\circ} \mathrm{C}$ ). The same applies to the compressor discharge temperature $\left(T_{2}\right)$, which in some tests, reached values close to the compressor operating limit and lubricating oil.

After the tests, the statistical treatment of the results was performed. The hypothesis test (ANOVA), was used to identify representative terms of model for each refrigerant. Fig. 2 presents the results of analysis of the mathematical model of the COP (coefficient of performance), to R22 fluid, that will be reference in this study. It can be seen that the adjusted coefficient of determination value $\left(\bar{R}^{2}\right)$ is bigger than 0.80 $\left(\bar{R}^{2}=0.9945\right)$, indicating good fit of the mathematical model. All analyzed values of $\left(\bar{R}^{2}\right)$, for all fluids were greater than 0.80 .

After the development and testing of models, look for by means of desirability function to find the best operating condition (optimum operating point), for specific evaporating temperatures, maximizing the set COP and $Q_{E V}$. It was defined three evaporation temperature for the $\mathrm{R} 22$ analysis, $-5{ }^{\circ} \mathrm{C},-10{ }^{\circ} \mathrm{C}$ and $-15{ }^{\circ} \mathrm{C}$. For these temperature, it obtained the optimum operating point, maximizing the desirability function with equal weights for these two dependent variables. The definition of weights in multivariate problems is always a critical decision, because it is individual of decision maker [19] and takes into account the application and need for each case. Fig. 3 shows the behavior of the desirability function and maximum values found for R22 with $T_{E V}=-10{ }^{\circ} \mathrm{C}$.

It can be seen in Fig. 3 that the selected points do not indicate the maximum COP or the maximum $Q_{E V}$. The objective of this step is to identify the optimum operation point for the R22 fluid.

The next step was to perform the optimization for alternative fluids, in search of points with the same conditions $\left(T_{E V}\right.$ and $\left.Q_{E V}\right)$ and the best COP, which will be used to compare with results of R22 fluid. Table 3 displays the result found for all analyzed fluids.

It is important to highlight that, for alternative fluids, the point shown in Table 3 is not the optimum operating, as defined for R22, which maximizes the desirability function (maximum set $\mathrm{COP}$ and $Q_{E V}$ ). The cooling capacity restriction implies a new function desirability, which results in a variation of COP (the best COP for a specific $Q_{E V}$ ). 


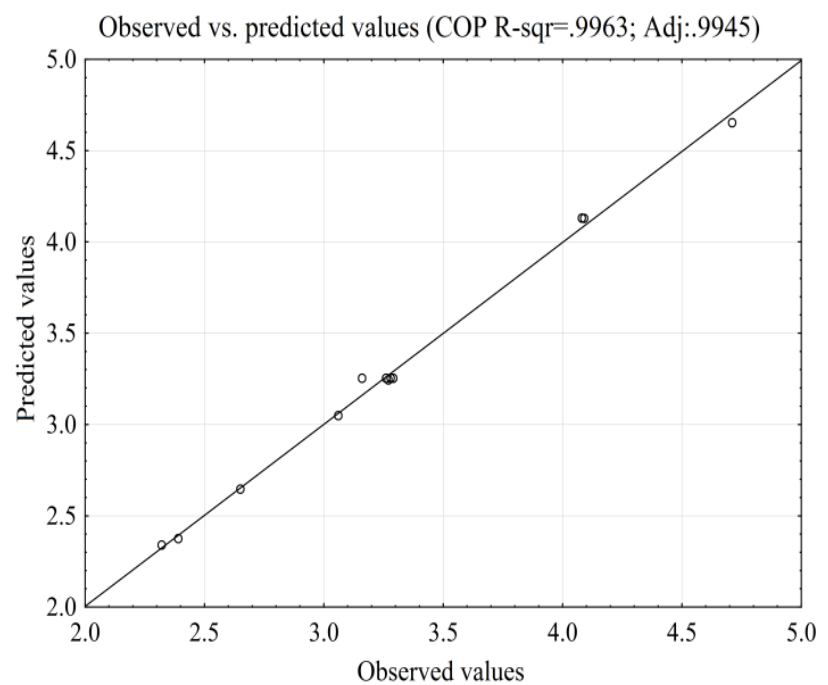

(a)

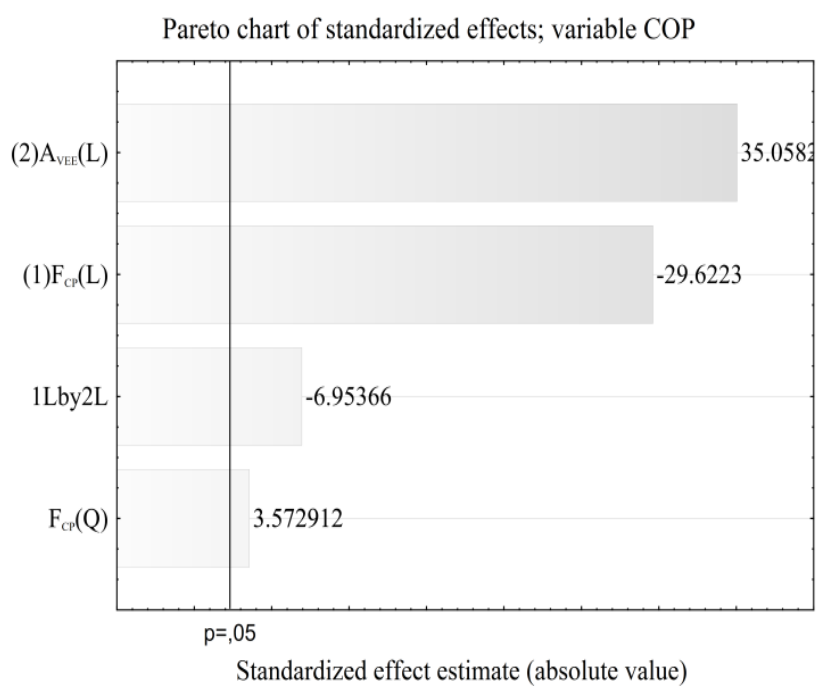

(b)

Fig. 2 Results of analysis of variance (ANOVA) for the COP parameter-Fluid: R22.

By analyzing the desirability function, it has been found that, for the R290, in all $T_{E V}$, the optimized value maximum has $Q_{E V}$ similar to that found in the analysis of R22 fluid, thus, the point shown in Table 3, is also the optimal operating point. This same condition occurs for the $\mathrm{R} 1270\left(T_{E V}=-15{ }^{\circ} \mathrm{C}\right)$, $\mathrm{R} 438 \mathrm{~A}\left(T_{E V}=-5{ }^{\circ} \mathrm{C}\right)$, R404A $\left(T_{E V}=-5\right.$ and $\left.-15^{\circ} \mathrm{C}\right)$ and $\mathrm{R} 410 \mathrm{~A}\left(T_{E V}=-15^{\circ} \mathrm{C}\right)$. In all other tests, the optimal point for the alternative fluid does not present the same refrigerating capacity of R22, which is to be considered normal due to differences in properties of fluids.

To R1270, $T_{E V}=-5$ and $-10{ }^{\circ} \mathrm{C}$, the maximum desirability point occurs with cooling capacity higher than in the R22. Thus, it was necessary to limit (reduce) the cooling capacity by the insertion of restriction condition in desirability function. This action resulted in an increase of COP.

The R410A $\left(T_{E V}=-10\right.$ and $\left.-15{ }^{\circ} \mathrm{C}\right)$ also presented $Q_{E V}$ upper, however, the restriction imposed on the desirability function (reduction cooling capacity), contrary to what happened with the R1270, resulted in reducing the COP. The same was observed with R32 $\left(T_{E V}=-5\right.$ and $\left.-10{ }^{\circ} \mathrm{C}\right)$, but at a lower intensity. To R32, $T_{E V}=-15{ }^{\circ} \mathrm{C}$, the $\mathrm{COP}$ was practically unchanged with limitation of $Q_{E V}$.
In the case of R404A $\left(T_{E V}=-10{ }^{\circ} \mathrm{C}\right)$, the optimum operating point was found with $Q_{E V}$ lower than observed for R22. In this case, to produce approximately the same cooling capacity than R22, the COP worsened (from 2.38 to 2.26).

With the R134a fluid, it was not possible to reproduce an operating condition that reached the same cooling capacity of R22 in the same evaporation temperature. The same occurs with $\mathrm{R} 438 \mathrm{~A}, T_{E V}=$ -10 and $-15^{\circ} \mathrm{C}$ and $\mathrm{R} 404 \mathrm{~A}, T_{E V}=-5^{\circ} \mathrm{C}$.

Through the analysis of the desirability function, we can observe the behavior of the dependent variables according on the factors tested (Compressor operating frequency and Degree of opening of electronic expansion valve). It is observed that all the analyzed factors ( $T_{E V}, Q_{E V}$ and COP) increase with increasing degree of opening of electronic expansion valve. With respect to compressor operating frequency, $T_{E V}$ and COP fall with increasing $F_{C P}$, while the cooling capacity grows. This divergent profile of parameters is one point that requires attention in optimization and complicates the use of weights.

In order to verify the quality of the methodology, the analysis was compared with the experimental results of tests performed by Antunes [21] in the same test bench, points of maximum cooling capacity 


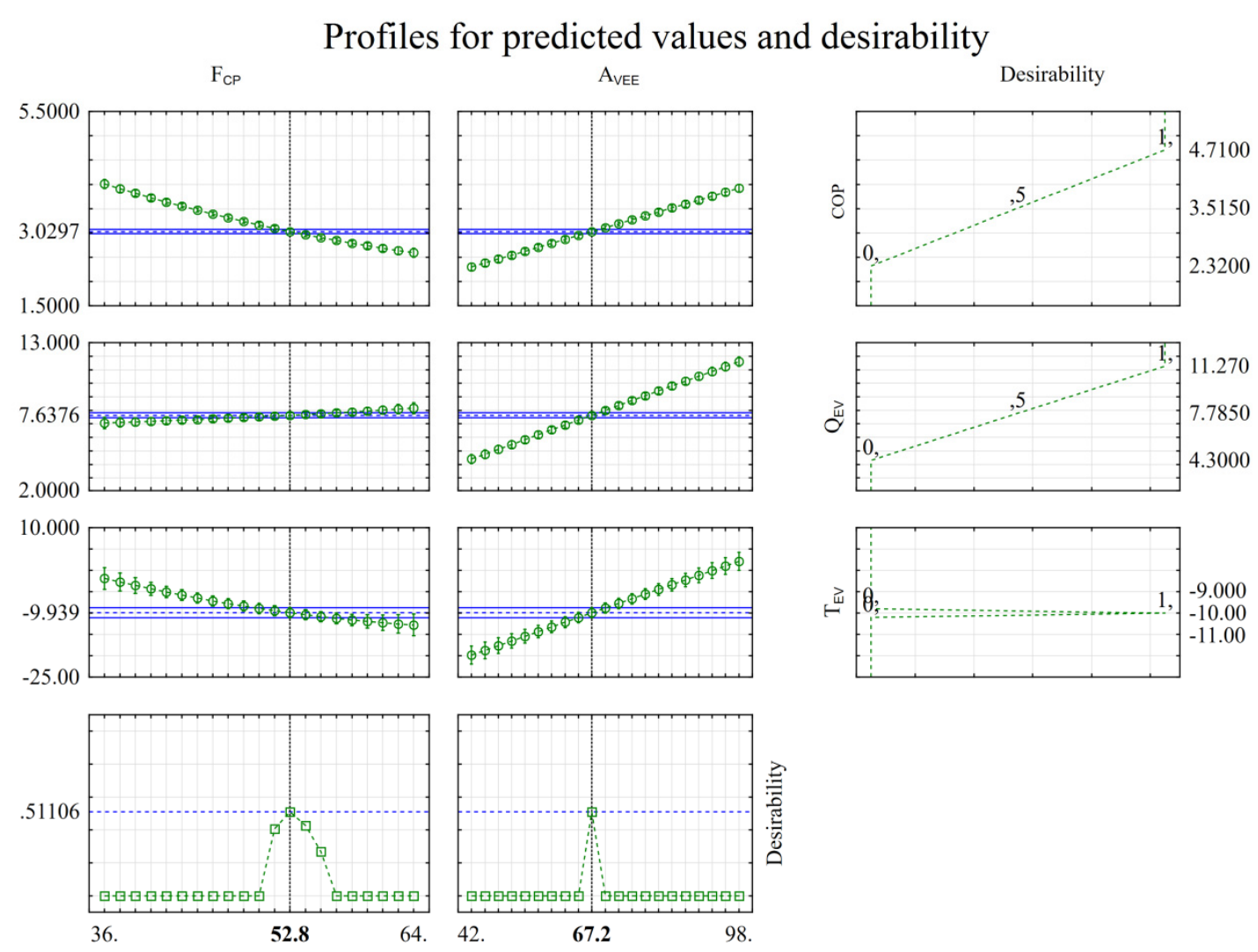

(a)

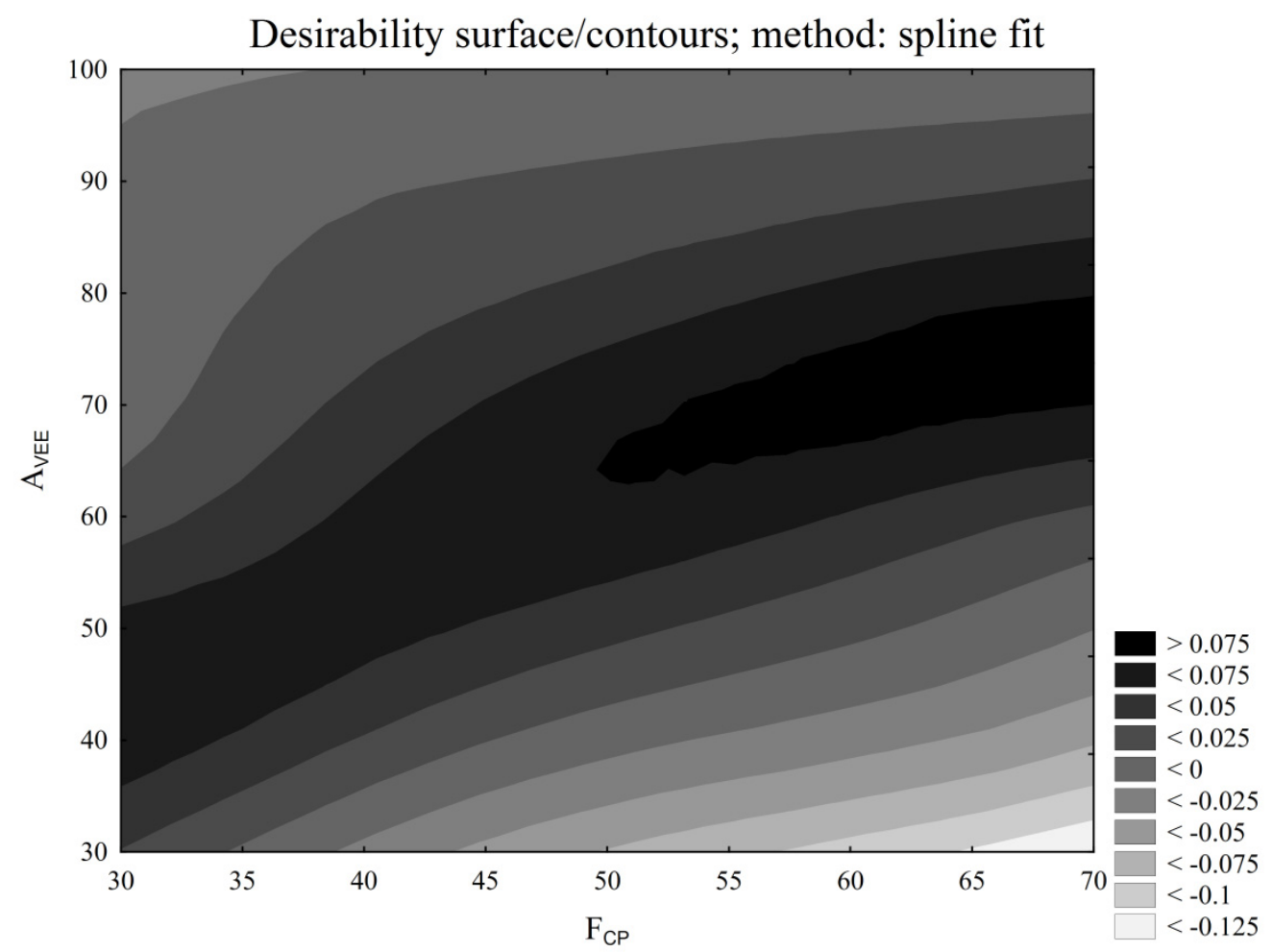

(b)

Fig. 3 Optimization of the desirability function for $\mathrm{R} 22$ and $T_{E V}=-10{ }^{\circ} \mathrm{C}$. 


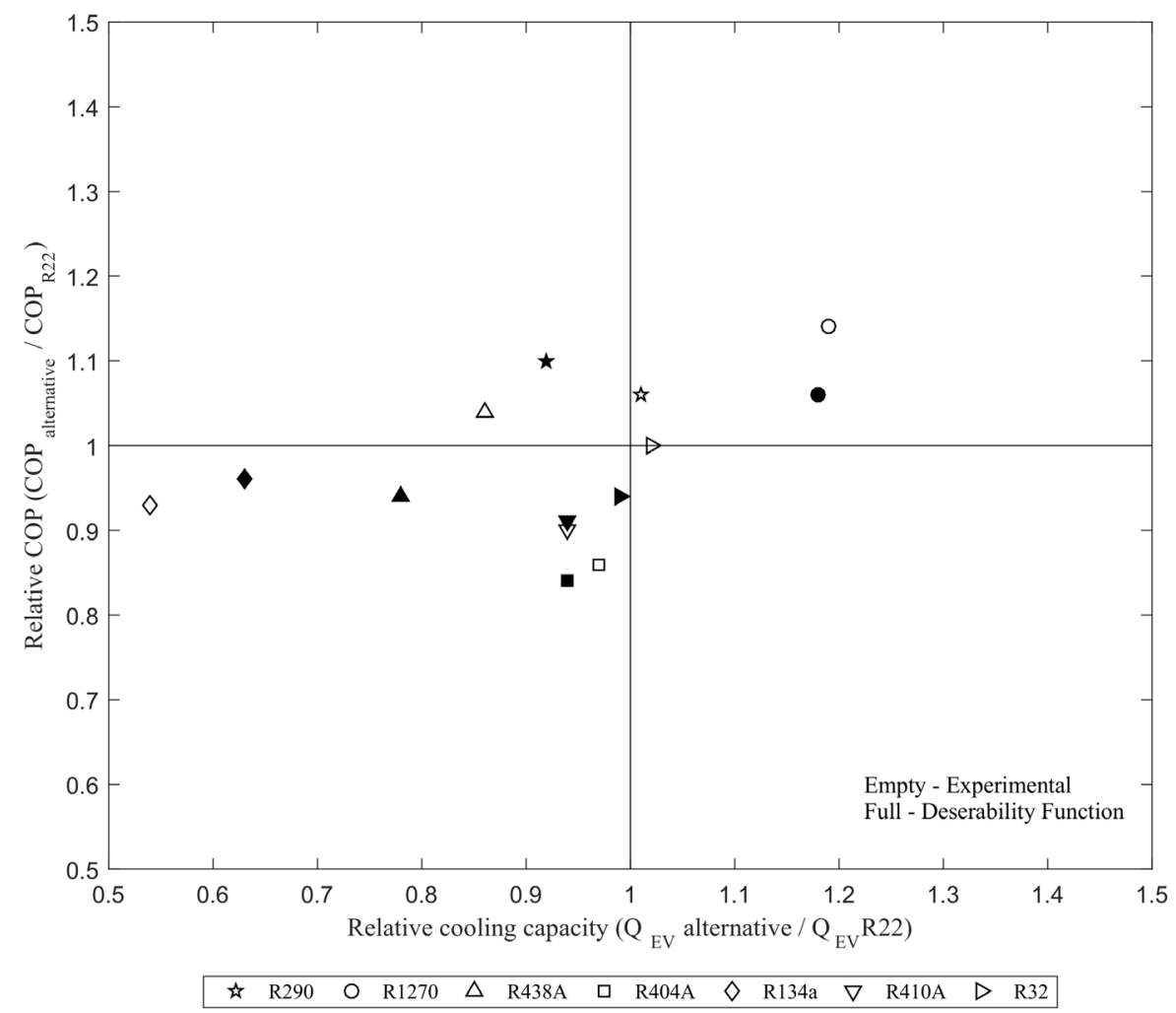

Fig. 4 Comparison of experimental and optimized results to maximum $Q_{E V}$ and $T_{E V}=-15^{\circ} \mathrm{C}$.

were selected in experimental research and compared to results of desirability function.

Approximately $56 \%$ of the points found with the mathematical model are between limits of measurement uncertainty. Some points outside this region can be explained due to the fact of desirability function has not calculated with the exact target temperature, adding to it an error in the results obtained by optimization function. Five measurements (approximately $10 \%$ ) need to be evaluated because they showed error bigger than $10 \%$, which may be posed by various causes, inclusive experimental error. Fig. 4 shows a comparison between experimental and calculated points of maximum $Q_{E V}$.

\section{Conclusions}

With the analysis of the desirability function, it was possible to identify the points or regions of maximum result (COP and $\left.Q_{E V}\right)$ and when it happens $\left(A_{V E E}\right.$ and $\left.F_{C P}\right)$. In addition, the function works well in the application of restrictions such as limits to $T_{E V}$ and
$Q_{E V}$. At this point, it is important to note that beyond these parameters, during the process of construction of response surfaces, other results were observed and not used in this work. With the desirability function, it is possible, for example, to verify the behavior of the fluid due to variation of condensing temperature, or even determine if in a drop-in operation, replacing a condenser or evaporator will be required to achieve the desired cooling capacity or improve the efficiency of operation.

Regarding the comparison between alternative refrigerants and R22, due to the difference found between the experimental points and the optimization model, should check the construction of curves and test procedures in order to reduce errors. Gains or losses obtained with the replacement of R22 for alternative fluids, are the same order of magnitude to the average error identified in the validation of methodology (comparing the experimental results with the mathematical model). In the analysis of deviation, it can be found a group of points that 
showed good convergence, indicating that use of this work is possible. It is important to identify and analyze the points with error upper to $10 \%$ to reduce the average error. Nevertheless, the desirability function can be used, in principle, in the previous selection of factors value, to reduce the number of tests.

\section{Acknowledgment}

The authors acknowledge the support given to the reported investigation by CAPES, CNPQ and FAPEMIG.

\section{References}

[1] Montreal Protocol on Substances That Deplete the Ozone Layer. 1987. 1522 UNTS 3; 26 ILM 1550.

[2] Kincl, M., Turk, S., and Vrečer, F. 2005. "Application of Experimental Design Methodology in Development and Optimization of Drug Release Method." International Journal of Pharmaceutics 291 (1-2): 39-49.

[3] Box, G. E. P., and Wilson, K. B. 1951. "On the Experimental Attainment of Optimum Conditions." Journal of the Royal Statistical Society Series B 13 (1): $1-45$.

[4] Montgomery, D. C., and Runger, G. C. 2003. Applied Statistics and Probability for Engineers. 3rd ed. New York, NY: John Wiley \& Sons, Inc.

[5] Özbayoglu, G., and Atalay, M. U. 2000. "Beneficiation of Bastnaesite by a Multi-gravity Separator." Journal of Alloys and Compounds 303-304: 520-3.

[6] Neto, B. D. B., Scarminio, I. S., and Bruns, R. E. 2001. Como Fazer Experimentos. Campinas, SP: Editora da Unicamp.

[7] Aslan, N., and Cebeci, Y. 2007. "Application of Box-Behnken Design and Response Surface Methodology for Modeling of Some Turkish Coals." Fuel 86 (1-2): 90-7.

[8] Bezerra, M. A., Santelli, R. E., Oliveira, E. P., Villar, L. S., and Escaleira, L. A. 2008. "Response Surface Methodology (RSM) as a Tool for Optimization in Analytical Chemistry." Talanta 76 (5): 965-77.

[9] Aslan, N. 2008. "Application of Response Surface Methodology and Central Composite Rotatable Design for Modeling and Optimization of a Multi-gravity Separator for Chromite Concentration." Powder Technology 185 (1): 80-6.

[10] Dharma, S., Masjuki, H., Ong, H. C., Sebayang, A., Silitonga, A., Kusumo, F., and Mahlia, T. 2016.
"Optimization of Biodiesel Production Process for Mixed Jatropha Curcas-Ceiba Pentandra Biodiesel Using Response Surface Methodology." Energy Conversion and Management 115 (December): 178-90.

[11] Ferreira, S. L. C., Bruns, R. E., da Silva, E. G. P., dos Santos, W. N. L., Quintella, C. M., David, M. J., and Neto, B. B. 2007. "Statistical Designs and Response Surface Techniques for the Optimization of Chromatographic Systems." Journal of Chromatography A 1158 (1-2): 2-14.

[12] Liu, Y. T., and Zhang, L. 2016. "An Investigation into the Aspheric Ultra Precision Machining Using the Response Surface Methodology." Precision Engineering 44 (2970378): 203-10.

[13] Ferreira, S. L. C., Bruns, R. E., Ferreira, H. S., Matos, G. D., David, J. M., Brandão, G. C., and Santos, W. N. L. 2007. "Box-Behnken Design: An Alternative for the Optimization of Analytical Methods." Analytica Chimica Acta 597 (2): 179-86.

[14] Rodrigues, D. M., Francisco, A., Augusto, F., Marins, S., Miranda, R. D. C., and Dias, É. X. 2015. Utilização da Otimização Multiobjetivo em Problemas de Delineamento de Experimentos Com Múltiplas Respostas. Guaratinguetá, SP.

[15] Derringer, G. C., and Suich, R. 1980. "Simultaneous Optimization of Several Response Variables." Journal of Quality Technology 12 (October ): 214-9.

[16] Sivertsen, E., Bjerke, F., Almoy, T., Segtnan, V., and Naes, T. 2007. "Multivariate Optimization by Visual Inspection." Chemometrics and Intelligent Laboratory Systems 85 (1): 110-8.

[17] Derringer, G. C. 1994. "A Balancing Act: Optimizing a Product's Properties.” Quality Progress 27 (8): 51-8.

[18] Dalvand, M. J., Mohtasebi, S. S., and Rafiee, S. 2014. "Optimization on Drying Conditions of a Solar Electrohydrodynamic Drying System Based on Desirability Concept." Food Science \& Nutrition 2 (6): 758-67.

[19] Costa, N., Loureno, J., and Pereira, Z. L. 2012. "Responses Modeling and Optimization Criteria Impact on the Optimization of Multiple Quality Characteristics." Computers and Industrial Engineering 62 (4): 927-35.

[20] Bukzem, A. L., Signini, R., Dos Santos, D. M., Lião, L. M., and Ascheri, D. P. R. 2016. "Optimization of Carboxymethyl Chitosan Synthesis Using Response Surface Methodology and Desirability Function." International Journal of Biological Macromolecules 85 (April): 615-24.

[21] Antunes, A. H. P. 2015. "Processo de substituição de R22 em sistemas de refrigeração comerciais." (Unpublished doctoral dissertation). The Federal University of Uberlândia. 